\title{
Yeni Nesil Demiryolu Traversleri ve Yerli FRP Donatı Kullanımının Deneysel Araştırması
}

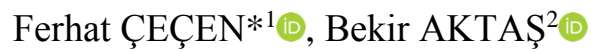 \\ ${ }^{1}$ TCDD Sivas Beton Travers Fabrikası Müdürlüğ̈̈, Sivas, Türkiye \\ ${ }^{2}$ Erciyes Üniversitesi, Mühendislik Fakültesi, İnşaat Mühendisliği Bölümü, Kayseri, Türkiye
}

*ferhatcecen@tcdd.gov.tr

(Alınış/Received: 01.10.2020, Kabul/Accepted: 03.11.2020, Yayımlama/Published: 31.01.2021)

Öz: Ülkemizde ve dünyada ulaştırma sektöründe demiryollarının payı gittikçe arttığından, demiryolu üstyapı elemanlarından biri olan traverslere duyulan talep de artmaktadır. Günümüzde dünya genelinde demiryollarında milyarlarca travers kullanımdadır. Yeni inşa edilen demiryollarının ihtiyacı olan travers üretiminin yanı sıra, 40-50 yıllık servis ömrünü tamamlayamadan erken deforme olan önemli miktarda traversin de her yıl değiştirilmeleri gerekmektedir. Bu yüzden demiryolu kuruluşlarının bütçelerinin önemli bir kısmı travers kaynaklı bakım işlemlerine ayrılmak zorundadır. Dünya genelinde milyarlarca travers üretiminin ekstra çimento, agrega, çelik, yakıt tüketimi doğurması nedeniyle çevreye önemli zararı söz konusu olduğu gibi modern demiryolu işletmeciliğinde yüksek hız ve sefer sayıları nedeniyle, düşük bakım gerektiren "yeni nesil" çözümler geliştirilmesi mecburiyet halini almıştır. Diğer taraftan inşaat sektöründe kullanılmakta olan çelik donatıların korozyon ve yorulma gibi çeşitli dezavantajları da bulunmaktadır. Bu kapsamda günümüzde gelişmiş ülkelerde çelik donatıların yerini almaya başlayan fiber takviyeli polimer (FRP) donatıların demiryolu traverslerinde kullanımı alternatif bir çözüm olarak görülmüştür. Bu makalede, klasik betonarme traverslerin güncel literatürde geçen çeşitli sorunlarına ve son yıllarda geliştirilen yeni nesil ç̧̈zümlere değinildikten sonra, bu sorunların yerli cam ve karbon fiber takviyeli polimer hammaddeler kullanılarak çözümlenebilme ihtimali ray mesnedinde statik yüklemeli pozitif moment deneyleri ile araştırılmıştır. Sonuçta dünyadaki emsallerinden daha düşük maliyetli ve daha yüksek servis ömrüne sahip inovatif milli travers modelleri geliştirilmesi adına olumlu sonuçlar elde edilmiştir.

Anahtar kelimeler: Yeni Nesil Demiryolu Traversleri, Fiber Takviyeli Polimerler (frp), Donatı Korozyonu ve Yorulması, Sürdürülebilir Ulaştırma, Servis Ömrü Odaklı Fizibilite Etüdü

\section{New Generation Railway Sleepers and Experimental Research of Domestic FRP Reinforcement Use}

\begin{abstract}
Billions of sleepers are used on railways around the world today. As the share of railways in the transportation sector is increasing, the demand for sleepers is also increasing. Due to the various capacity problems of the sleepers, a significant number of them need to be replaced every year. For this reason, a significant part of the budgets of the railway organizations have to be devoted to sleeper maintenance operations. On the other hand, "new generation" feasible solutions have become compulsory due to the high speed modern railway operations. Production of billions of sleepers have significant environmental damage due to extra cement, aggregate, steel and fuel consumption. Today, many countries around the world have various sleeper patents suitable for their operating conditions and local resources. In addition, in the "new generation" sleeper models; high-cost solutions that can meet today's low maintenance requirements have become a must. On the other hand, steel reinforcements used in the construction industry have various disadvantages such as corrosion and fatigue. In this context, the use of fiber reinforced polymer reinforcements in railway sleepers, which has started to replace steel reinforcements in developed countries, has been seen as an alternative solution. In this article, after mentioning the various problems of existing reinforced concrete sleepers in the current literature, the possibility of solving these problems by using domestic glass and carbon fiber reinforced polymer raw materials is investigated in the light of experimental studies. As a result, positive results have been obtained in terms of developing innovative national sleeper models with lower cost and higher service life than their counterparts in the world.
\end{abstract}

Atıf için/Cite as: F. Çeçen, B. Aktaş, "Yeni nesil demiryolu traversleri ve yerli FRP donatı kullanımının deneysel araştırması," Demiryolu Mühendisliği, no. 13, pp. 53-64, Jan. 2021 doi: 10.47072/demiryolu. 803452 
Keywords: New Generation Railway Sleepers, Railroad Ties, Fiber Reinforced Polymers (frp), Reinforcement Corrosion and Fatigue, Sustainable Transportation, Life Cycle Assessment

\section{Giriş}

Klasik demiryollarının bileşenleri, üstyapı ve altyapı olarak kategorize edilmektedir. Raylar ve traversler "üstyapı"; balast ve formasyon tabakası "altyapı" bileşenleridir. Traversler, raylardan aldığı yük ve titreşimleri, altyapıya sönümleyerek aktarmakta ve yol geometrisini korumakta büyük öneme sahiptir. Raylı sistemlerde, geçmişte ahşap ve çelik traversler kullanılmışsa da bugün dünyada en çok kullanılan travers tipi betonarme traverslerdir. Betonarme traversler üretim prosesine ve geometrisine bağlı olarak Şekil 1'de örnekleri verilen şu sınıflarda üretilmektedir:

a) Öngerilmeli traversler (Alman/İngiliz ekolü, prestressed concrete sleepers):

i. Tek parçalı geometri (yekpare, mono-block), 55-60 $\mathrm{cm}$ aralıkla konumlandırılır.

- Ard-germeli (post-tensioned): Ard-germe işlemi, beton dayanım kazandıktan sonra direkt betona uygulanmaktadır (yaygın değildir).

- Ön-germeli (pre-tensioned): Ön-germe işlemi, beton dayanım kazanmadan önce betonla birlikte kür gören çelik kalıp tarafından taşınmakta, beton dayanım kazandıktan sonra serbest bırakılarak betona aktarılmaktadır (Şekil 1.a, 1.c).

ii. Tek parçalı geometri, kesintisiz (döşeme tipi) konumlandırılır, yaygın değildir.

b) Öngerilmesiz traversler (Fransiz ekolü, traverse en béton armé).

i. İki simetrik parça halinde geometride (ikiz-blok, twin-block, bi-blocs) (Şekil 1.b).

ii. Tek parçalı geometri (yekpare, mono-block) (yaygın değildir).

iii. Tek parçalı geometri, kesintisiz (döşeme tipi) konumlandırılır (Şekil 1.d), yüksek ilk yatırım maliyetli ancak servis ömrü bazında düşük bakım maliyetli olduğundan yaygındır.

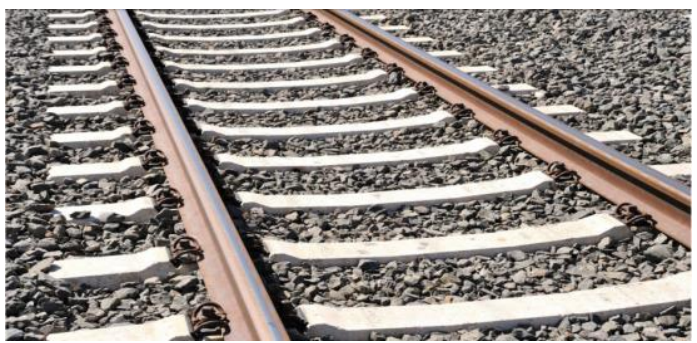

a)

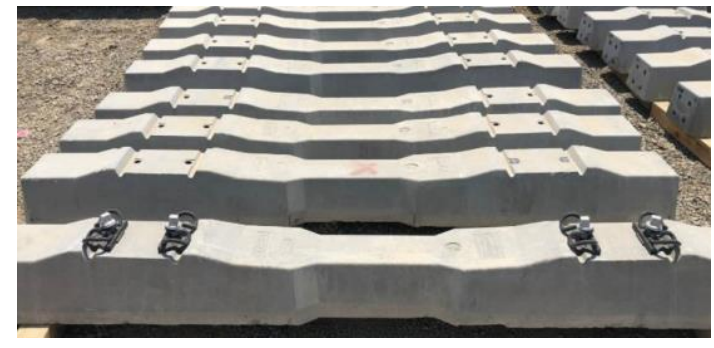

c)

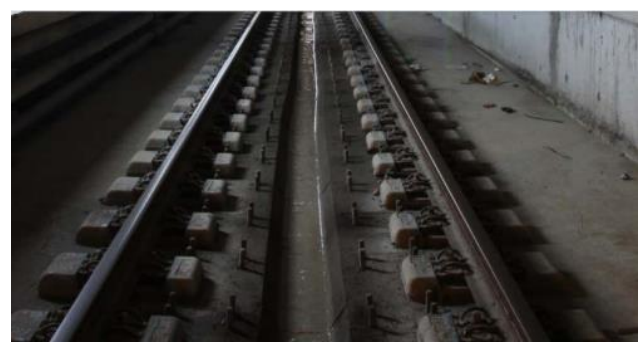

b)

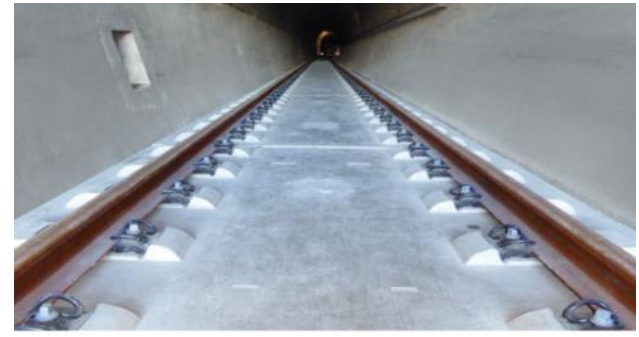

d)

Şekil 1. Bazı travers çeşitlerinin ülkemizdeki örnekleri: a) Ankara-Konya hızlı tren hattındaki B70 tipi mono-blok öngerilmeli travers, b) Marmaray hattındaki LVT tipi ikiz-blok öngerilmesiz travers (sağ-üst), c) Ankara-Sivas hızlı tren hattındaki B07 tipi mono-blok öngerilmeli travers, d) Ankara-Sivas hızlı tren hattındaki slab-track tipi kesintisiz döşeme tipi traversler

Demiryollarında, işletim koşullarına (hız, dingil yükü, hat açıklığı, altyapı ve üstyapı bileşenleri vb.) bağlı olarak değişkenlik göstermekle birlikte, örneğin ülkemizin de üyesi olduğu UIC (Dünya Demiryolu Birliği) hatlarında yaklaşık 55-60 cm mesafelerle konumlandırılan traversler için tüm dünyada büyük bir tüketim söz konusudur. Dünya genelinde yaklaşık 3 milyar travers 
kullanımdadır. Traverslerin bu kadar yoğun üretilmelerinin nedenlerinden biri önemli bir kısmının hedeflenen 40-50 yıl servis ömrüne ulaşamamasıdır. Traverslerin her yıl \%2-5'inin hasarlandığı için değiştirilmesi gerektiği ve bu maliyetin demiryolu bakım masraflarının yaklaşık \%12'sine tekabül ettiği belirtilmektedir [1]. Demiryolu bakım prosedürlerine göre, özellikle öngerilmeli traverslerde, öngerilme kapasitesini düşürecek ve donatının korozyona uğramasına neden olabilecek büyüklükte çatlak tespiti halinde, derhal değiştirilmeleri gerekmektedir. İsveç’te 3 milyon traversin gözle muayenesi yapılan bir araştırmaya göre, 500 bin adedinde gözle görülebilir çatlaklar tespit edilmiştir [2].

Ülkemizde 11.000 kilometrenin üzerinde demiryolu ağı bulunmakta olup, yaklaşık 18 milyon traverse tekabül etmektedir. Bu rakamlarda inşası devam eden ve inşa edilecek hatlar dâhil değildir. Ülkemizde yeni inşa edilen demiryolu hatları hariç tutulursa, mevcut hatların bakım işlemleri için her yıl yaklaşık 1 milyon travers teminine ihtiyaç duyulmaktadır. 2020 yllı için 1 adet betonarme traversin maliyeti ortalama 300-400 TL'dir. Traverslerin üretim, nakliye ve değişim maliyetlerinin haricinde, her yeni travers üretiminin ekstra çimento, agrega, çelik, yakıt tüketimi nedeniyle çevreye zararı da söz konusudur. Ayrıca erken deforme olan traversler değiştirilinceye kadar diğer daha pahalı demiryolu bileşenlerine de (milyon dolarlık hızlı tren setleri, köprüler, viyadükler, raylar, bağlantı malzemeleri -zemin-tren seti) zarar vermektedir. Bir diğer açıdan, demiryolu geometrisinde erken deforme olan traversler nedeniyle meydana gelen geometrik bozulmalar nedeniyle yolculuk konforu olumsuz etkilenmekte, hiz kisitlamaları veya yol kapanmaları nedeniyle ticari ve sosyal prestij kaybı meydana gelebilmektedir. Günümüzde tüm dünyada demiryolu işletim kapasitesi (günlük sefer sayısı) arttıkça, bakım işlemleri için ayrılabilecek süreler de azalmakta, geceleri örneğin 01:00-04:00 saatleri arasında birkaç saat içerisinde tamamlanabilecek, düşük bakım gerektiren demiryolları inşası "mecburiyet" halini almaktadır. Günümüzde dünyada en yaygın kullanılan öngerilmeli betonarme traverslerin birçok avantajı olsa da, darbe sönümleme kabiliyeti düşük olan ve kolayca rezonansa uğrayan bu traversler özellikle tünel, köprü, viyadük gibi zemin stabilitesi mevcut ve rijitliği yüksek zemin şartlarında kullanılamamaktadır. Bu tarz lokasyonlarda; $120 \mathrm{~km} / \mathrm{sa}$ ve altı hızlarda işletme söz konusu ise sönümleme kabiliyeti öngerilmeli traverslerden daha iyi olan Şekil 2.a'daki geleneksel ahşap traversler kullanılmaktadır. Ancak son yıllarda ahşap travers temininde yaşanan zorluklar ve çevresel etkenler düşünülerek, çok daha yüksek maliyetli kompozit/plastik traversler geliştirilmiş ve çeşitli hat kesimlerinde kullanılmaya başlanmıştır. Şekil 2.b ve 2.c'de örnekleri verilen bu traversler, ahşap traverslerin alternatifi olarak geliştirilmiş olup, düşük kütleleri nedeniyle yüksek hat stabilitesi istenilen hızlı tren hatlarında kullanılamamaktadır. Ayrıca erken yorulma, yüksek maliyet, düşük kapasite vb. nedenlerle istenilen düzeyde yaygınlaşmamıştır [3].

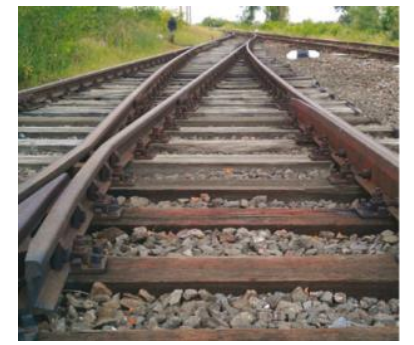

a)

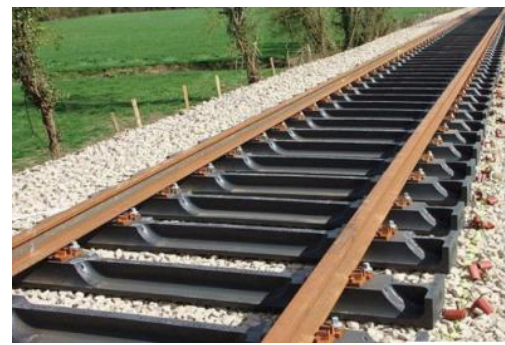

b)

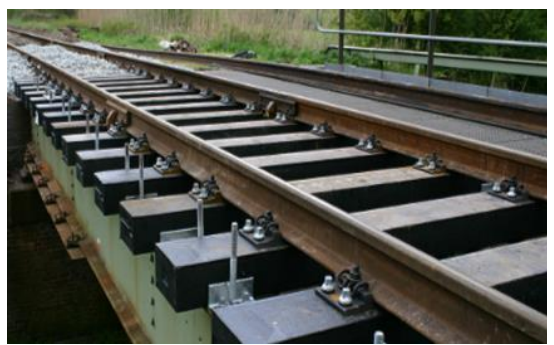

c)

Şekil 2. Ahşap traversler (a) ve alternatifi olarak geliştirilen kompozit traversler (b, c)

Gelişen demiryolu işletim şartları altında, daha yüksek nitelikli üstyapı ve altyapı tesislerine ihtiyaç duyulmuştur. Bu doğrultuda, günümüzde, $120 \mathrm{~km} / \mathrm{sa}$ ve üstü işletme hızlarında ve hafif raylı şehir içi hatlarda ve ağır yüklü şehirlerarası hatlarda, özellikle tünel, köprü, viyadük gibi zemin stabilitesi mevcut ve rijitliği yüksek zemin şartlarında; öngerilmeli betonarme traversler yerine Şekil 1.d ve 3'te örnekleri sunulan kesintisiz "floating slab-track" tipi (1 traverslik alan için $\approx 780 \mathrm{~kg}$ ) veya HAS (High Attenuation System) tipi betonarme uygulamalar kullanılmaya 
başlanmıştır. Örneğin ülkemizde, hâlen devam etmekte olan Kayaş-Sivas Hızlı Tren Hattında bugüne kadar 33.000 adet Şekil 1.d'de görülen slab-track tipi travers kullanılmış olup, 156 kilometreye tekabül etmektedir. Tüm projenin yaklaşık $393 \mathrm{~km}$ olduğu düşünülürse, söz konusu yüksek ilk maliyetli yeni nesil traverslerin yeni projelerde ne kadar yaygınlaştığı bariz olarak görülecektir. Bu traversler, standart B70 tipi traverslerden yaklaşık 3 kat daha büyük hacme ve yüksek maliyete sahiptir. Bu yüksek ilk yatırım maliyetli "yeni nesil" traversler, travers üretim, nakliyat ve montaj maliyeti artmasına ve işçiliği zorlaşmasına rağmen, yukarıda değinilen birçok faydalarından ötürü git gide daha yaygın olarak kullanılmaya başlamıştır. Günümüzde artık yeni travers projeleri geliştirilirken, ilk yatırım maliyetinin dışında, daha gerçekçi olan "bakım/kullanım ömrü odaklı fizibilite etüdü” (LCA, life cycle assessment) uygulanmaktadır.

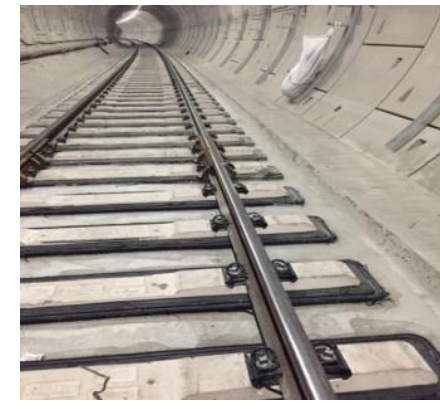

a)

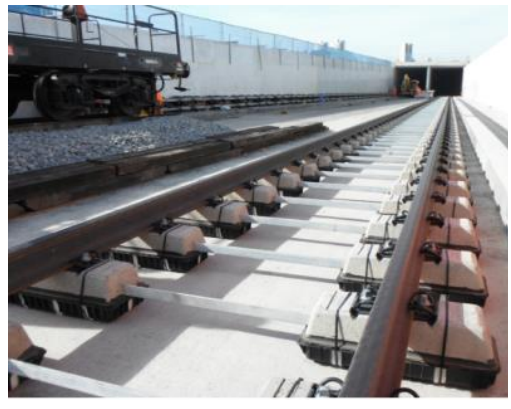

b)

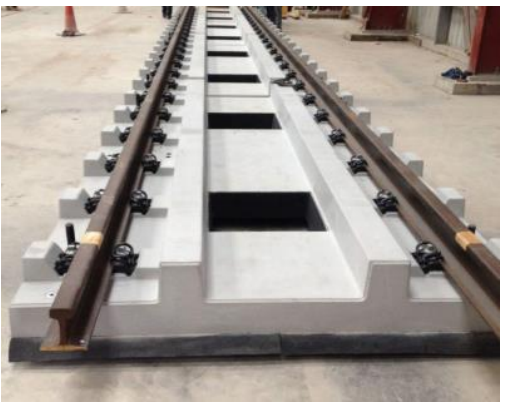

c)

Şekil 3. Dünyadaki HAS (High Attenuation System) (a,b) ve floating slab-track (c) tipi travers örnekleri

Günümüzde, yukarıda belirtilen özel lokasyonlardaki dönüşüm, normal hatlarda dahi mevcuttur. Örneğin Avusturya'da çift H tipi (double H-shaped, Şekil 4.a) ve çerçeve tipi (frame, Şekil 4.b) betonarme traversler geliştirilmiştir. Çift $\mathrm{H}$ tipi traverslerin genişliği $95 \mathrm{~cm}$ 'e yükseltilmiş (yaklaşık 3-3,5 kat), bağlantı malzemeleri iki kat fazla kullanılmıştır. Ayrıca traversler arasına yarı-sürekli seyir sağlayan, üzerinde plastik selet yapışık vaziyette üretilen ara traversler monte edilmektedir. Bu traverslerde ayrıca travers altına, travers ebadında, sönümleyici plastik pedler konulmaktadır. Almanya' da ise geniş travers (wide-sleeper, Şekil 4.c) olarak adlandırılan yeni bir travers modeli geliştirilmiş olup, travers eni (B70 tipinde $30 \mathrm{~cm}$ iken) $57 \mathrm{~cm}$ 'e yükseltilmiştir $(560 \mathrm{~kg}$ ). Demiryoluna monte edildiklerinde traversler arasında yalnız $3 \mathrm{~cm}$ boşluk kalmakta olup, bu boşluk da kauçuk ile doldurulmaktadır. Travers üretimindeki ilave masrafların orta vadede bakım masraflarında sağlayacağı tasarruf ile amorti edileceği raporlanmıştır [4].

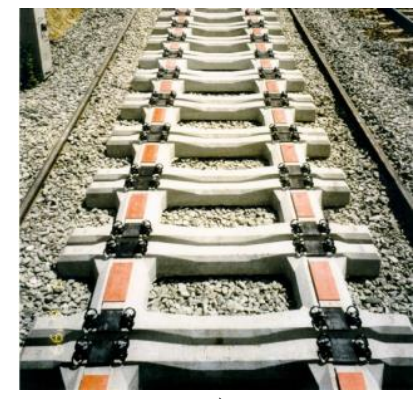

a)

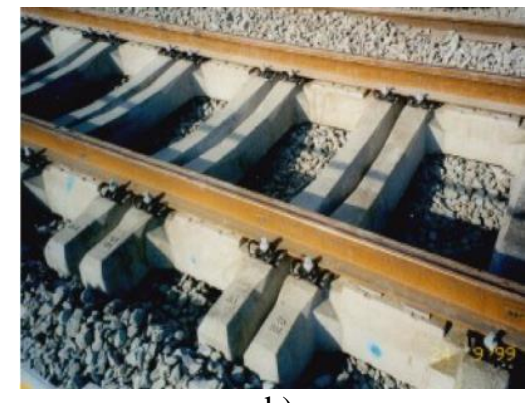

b)

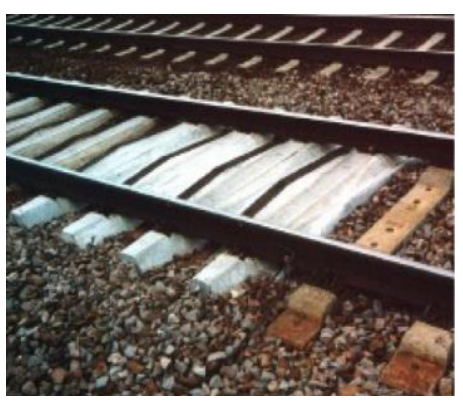

c)

Şekil 4. Dünyada son yıllarda geliştirilen diğer travers tipleri: a) Avusturya patentli çift-H tipi travers,

b) Avusturya patentli çerçeve travers c) Alman patentli geniş travers [4]

Son 20-30 y1ldır dünya genelinde demiryolu kuruluşları ve akademisyenler, bir yandan kesit boyutları ve donatı düzeni değişik traversler geliştirirken, bir yandan da mevcut traverslerin ömürlerinin erken safhalarında kullanılamaz hale gelmelerinin ana nedenlerini araştırmaktadır. İyi bir demiryolunda, ray üzerinde "pürüzsüz" bir yüzey ve taşıt tekerlerinin "tam dairesel" olması istenmektedir. $\mathrm{Bu}$ tarz hatlarda demiryolu taşıtları genellikle ( $20 \mathrm{~Hz}$ 'in altında) düşük frekanslı titreşimler oluşturmaktadır. Bu yolda oluşan kuvvetler yalnız statik ve tren hızına bağlı olarak 
yarı-statik yükler olacaktır [5]. Ancak "kaçınılamaz şekilde" zamanla tekerlerde ve raylarda anormallikler oluşmakta ve (2000 Hz'e varan) daha yüksek frekanslar ve dolayısıyla daha yüksek yükler meydana gelmekte olup, bunlara dinamik teker-ray yükleri veya darbe yükleri (impact loads) denmektedir [2]. Demiryollarında son 10-20 yıla kadar dizayn edilen traverslerin tasarımında, inşaat mühendisliğinde artık kullanımı oldukça azalan, "izin verilebilir gerilme metodu" (allowable stress design method) kullanılmıştır. Bu metotta, traverslerin yorulma ve darbe dizayn yükleri belirlenirken, statik hesaplamalarla bulunan teker yükü (static wheel load), belirli hesaplamalara dayanmayan güvenlik katsayılarıyla (impact factor) artırılmaktadır. Ülkemizde de yaygın olarak kullanılmış B58 tipi (dizayn yılı 1958) ve kullanılmakta olan B70 tipi (dizayn yılı 1970) traverslerde bu metot ile hesaplamalar yapılmıştır. B70 tipi öngerilmeli betonarme traverslerin EN 13230 normuna göre demiryolu kuruluşlarınca istenen yorulma esaslı dizayn yükü (fatigue design load) $150 \mathrm{kN}$, travers servis ömrü (40-50 yıl) içerisinde yalnızca birkaç defa görülmesine izin verilen istisnai darbe yükü (exceptional design load) $270 \mathrm{kN}$ ve travers servis ömrü boyunca 1 defa görülmesine izin verilen kırılma yükü (accidental design load) 375 kN'dur. Bu değerler değinildiği üzere; inşaat mühendisliğinde artık kullanımı oldukça azalan, "izin verilebilir gerilme metodu" kullanılarak hesaplanmıştır.

Modern "limit durum dizayn metodunda" (limit state design method) ise gerçek saha ölçümlerine ihtiyaç duyulması nedeniyle son yıllarda dünyanın çeşitli bölgelerinde saha ölçümleri artırılmıştır. $\mathrm{Bu}$ amaçla demiryolunda belli süre ile sensörler yerleştirilerek (Wheel Impact Load Detector, WILD) gerçek tren yükleri kayıt altına alınmaktadır. Örneğin, Queensland University of Technology (Avustralya) tarafından 2004 yılında, 12 ay süreyle, boş/dolu yaklaşık 6 milyon dingil kaydı tutulmuştur. Söz konusu saha araştırmasının istatistikî sonuçları Şekil 5'te sunulmuştur. Kayıt sonuçlarına göre \%96'lık dilim $50 \mathrm{kN}$ ve altıdır. Ancak çalışma yapılan yıl içerisinde 100.000 adet bu yükü aşan ve 310 kN'a varan darbeler meydana gelmiştir [6].

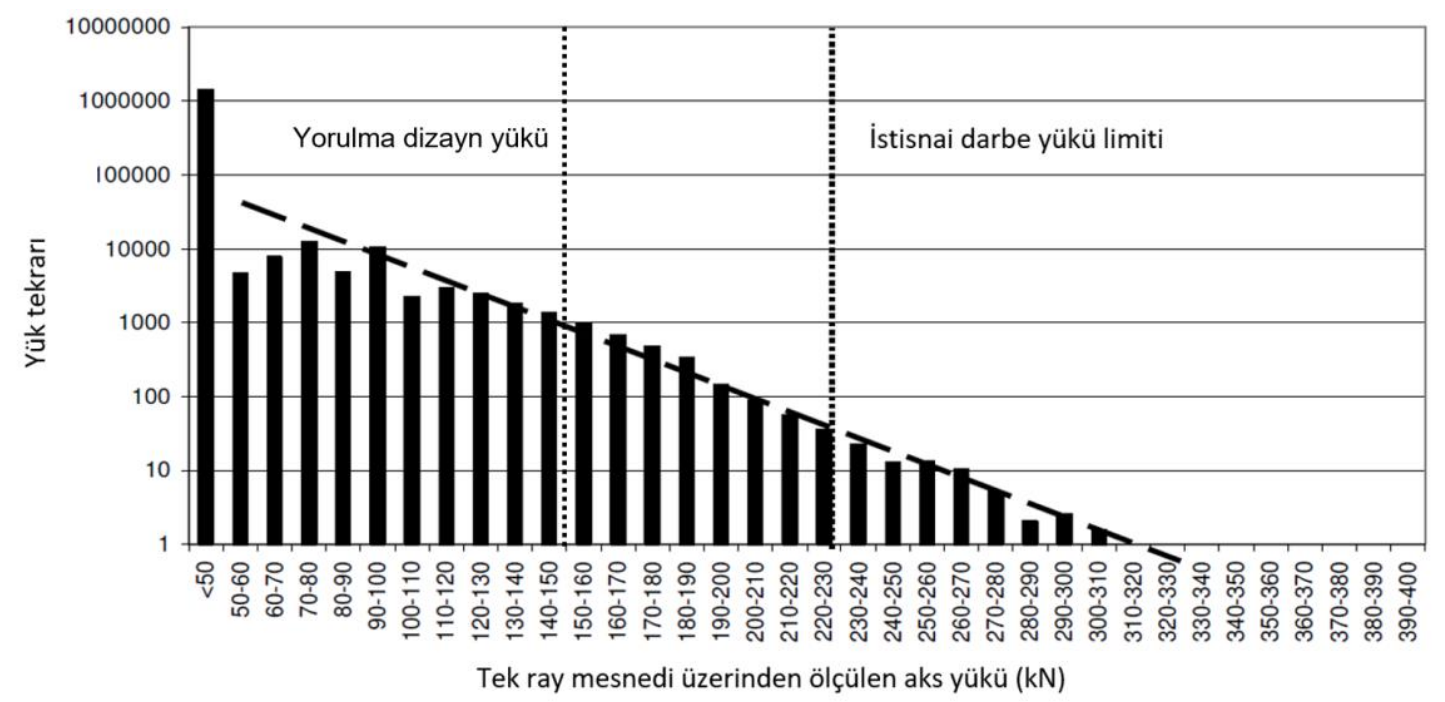

Şekil 5. Queensland University of Technology saha ölçümleri sonuçları [6]

Saha ölçümlerinin yapıldığı Avustralya'da demiryolu işletim şartları UIC (Uluslararası Demiryolu Birliği) normlarından farklı olup, UIC hatlarında yapılacak travers dizaynlarında birebir kullanılması doğru olmamakla birlikte, mevcut dizayn yükleri ile gerçek saha ölçümlerinin kıyaslanması adına yeterli derecede fikir vermektedir. Bu örnekteki 12 aylık saha kaydına göre, klasik traverslerin yorulma dizayn yükü olan 150 kN'u aşan yük adedi y1llık yaklaşık 3500 adet ve isitisnai darbe yükünü aşan ve 310 kN'lara varan yük adedi ise 100 adettir. Bu çalışmaya benzer olarak dünyanın çeşitli ülkelerinde yapılmış olan birçok saha kaydına literatürde ulaşılabilmektedir. Söz konusu istatistikler en fazla 12 aylık süreçte ve kısıtlı bir lokasyonda elde 
edilmiş, buna rağmen 750 kN'a varan darbe yükleri kayda geçmiştir [5], [7], [8], [9], [10]. Bu ölçümlere ait sonuçlar hat eskidikçe ve geometrik özellikleri bozuldukça daha da artacaktır. Nitekim travers altı zemin düzenleme (buraj) işleminin, travers orta noktasındaki eğilme momentini \%63 oranında düşürdügü tespit edilmiştir [7]. Sonuç olarak, traverslerin hedeflenen 40-50 yıl servis ömrüne ulaşmadan deforme olması ve bakım çalışmalarının artması nedeniyle, dizayn noktasındaki bu eksikliği gidermek için kullanıcıların, traversler arası $60 \mathrm{~cm}$ 'lik mesafeyi daraltarak, traversler üzerine gelen yükleri azaltması oldukça yaygındır. Bu uygulama, yeni nesil slab track vb. döşeme tipi traverslerdeki bakım ihtiyacının düşürülmesiyle benzerdir. Demiryollarında traverslerin dizaynında standart inşaat mühendisliği yapılarından farklı olarak, tesir eden yük yalnızca dinamik (hareketli) yüklerdir ve etki süreleri kısa (1-20 ms) fakat tekrar sayıları ve frekansları yüksektir (2000 Hz'e varan ortalama 80 milyon yük tekrarı). Sonuç olarak; son yıllarda diğer inşaat mühendisliği yapılarında olduğu gibi demiryolu traverslerinde de modern limit durum dizayn metodu kullanılmaya başlamıştır. Bu metotta dizayn yükü belirlenirken; saha ölçümlerinden elde edilen "gerçek" sonuçlar, yapı önem katsayısı ve dizayn ömrü hedefine bağlı olarak probabilistik yaklaşımla güvenlik katsayısına tabi tutulmaktadır. Bu metotla yapılan hesaplamalar doğrultusunda, konvansiyonel traverslerin yetersiz kaldığı görülmüş ve daha önce örnekleri verilen "yeni nesil" traversler üretilmeye ve yaygınlaşmaya başlamıştır. Bu metot doğrultusunda travers dizaynlarının nasıl yapılacağı örneğin EN 13230-6:2020 standardında detaylı olarak açıklanmıştır. Bu standart henüz Türk Standartları Enstitüsü iş planında olup, ülkemizde önümüzdeki 3-4 yıl içerisinde yürürlüğe girmesi öngörülmektedir. Travers dizaynında bu gelişmeler yaşanırken, travers kabullerinde halen eski izin verilebilir gerilme metoduna dayalı testler devam etmektedir. Söz konusu testlerin demiryollarındaki gerçek şartları tam olarak simüle edememesinin 4 temel nedeni şu şekilde öngörülmektedir:

1) Demiryolu traversi standartlarına göre (EN-13230, AREMA, AS-1085 vb.) yorulma testlerinde 2 veya 3 milyon yük tekrarı uygulanmaktadır. Ancak Eurocode 2 (CEN, 2005) normu doğrultusunda yapılan hesaplamalara göre traverslere servis ömrü boyunca etkiyen yük tekrarı sayısı yaklaşık 80 milyondur [10]. Yani yorulma testindeki tekrar sayısı, hedeflenen servis ömründeki tekrar sayısının binde 25 'ine tekabül etmektedir.

2) Günümüzde UIC normlarına ve EN 13230 standardına göre 22,5 ton.f dingil yüküyle işletilen hatlarda kullanılan B70 tipi traverslerin yorulma (fatigue) testlerinde uygulanan yük çevrim aralığı 50-150 kN'dur. Bu yük değerleri izin verilebilir gerilme metoduyla hesaplanmış olup, güncel saha ölçümleri açısından -hattın bakım durumuna ve işletim hızına bağlı olarak- yeterli gelmeyebilecektir. Bu yüzden mevcut EN 13230 yorulma testleriyle yeterlilik alan traversler, sahada bir müddet kullanıldıktan sonra tekrar aynı $150 \mathrm{kN}$ 'luk yorulma deneyini çoğu zaman geçememektedir. Örneğin, demiryolundan alınan 13 adet eski traverste standart yorulma deneyi uygulanmış, 7 adet traversin EN 13230'da geçen 2 milyon çevrimli yorulma deneyini geçmediği rapor edilmiştir [2]. Yine benzer olarak; yaklaşık 4-5 yıllık süre akabinde, traverslerin elastisite modülünün $37 \mathrm{GPa}$ değerinden 26,2 GPa'a düştüğü rapor edilmiştir [10].

3) Gerçek şartlar altında demiryollarında traversler her türlü dış etkene açıktır. İsveç’te 3 milyon traversin gözle muayenesi yapılan bir araştırmaya göre, 500 bin adedinde gözle görülebilir (makroskobik) çatlaklar tespit edilmiştir [2]. Demiryolu traversleri her türlü dış etkene açık olduğundan, bu çatlaklardan sizan su-nem-klorid iyonu maruziyeti ile mevcut traverslerde kullanılan çelik donatıların korozyona uğraması kaçınılmazdır. Litvanya'da demiryolunda yalnız 3 yıl süreyle kullanılmış traverslerin donatı korozyon düzeyinin araştırıldığı deneysel bir araştırmada, traverslerde mevcut korozyon kaynaklı hasarın 40 mm'lik çapa ulaşabildiği kaydedilmiştir [8]. Bir diğer açıdan, hızlı tren hatları yüksek gerilimli elektrikle işletildiğinden, çelik rayların ve çelik donatı içeren traverslerin, "elektrik akımının etkisiyle" daha hızlı korozyona uğrayacağı literatürde belirtilmektedir [11], [12]. Ayrıca öngerilmeli traverslerde öngerilmeli sistem sayesinde daha düşük çaplı donatılar kullanıldığından, minimal korozyon maksimal kapasite kayıpları doğurmaktadır [13].

4) Özellikle öngerilmeli traverslerde, rötre, sünme, termal genleşme, 1sıl kür hataları vs. nedeniyle zamanla kapasite kayıpları meydana gelmektedir. Bu yüzden öngerilmeli travers tasarımında öngerilme kuvvetinin yaklaşık \%25'inin kaybolacağı öngörülmektedir [14]. 
Öngerilme kayıplarının 15 yıl ardından \%30 düzeyine ulaşması tahmin edilmekte, sıcaklık değişimi ile travers ortasındaki eğilme momentinde \%25 (ayrı bir) kayıp ölçülmüştür [15]. Özellikle nemce kuru iklimlerde \%30 öngerilme kaybı oluşması beklenmektedir [16].

5) Öngerilmeli proseste, traversler demiryoluna monte edilmeden (proje yükleri tesir etmeden) önce travers donatılarına gerilme uygulanarak basınç kuvvetine dayalı bir ön kapasite sağlanmaktadır. Bu traverslerde tren yükü tesir etmediği müddetçe travers merkezine doğru sürekli etkiyen öngerilme basıncı mevcuttur. Bu ilave kapasite sayesinde belli bir yük değerine $\left(\mathrm{Fr}_{0}\right)$ kadar traverste çatlak meydana gelmez. Tren yükleri tesir ederken, tekrarlı olarak bu basınç sıfira doğru düşer ve tesir eden yük öngerilme kapasitesinden $\left(\mathrm{Fr}_{0}\right)$ fazla ise negatife düşer. Traverslerin dizayn yüklerini aşan yüklere maruz kalması ile, öngerilme kuvveti 4. maddede belirtilen oranlardan daha yüksek ölçüde kaybedilmektedir. Bu yüzden öngerilmeli prosesle üretilen traverslerin yorulma dizayn yükünden $\left(\mathrm{Fr}_{0}\right)$ fazla yüklere maruz kalması istenmez ve EN $13230 \mathrm{vb}$. standartlarda bu limitin üstündeki yüklere istisnai (exceptional) denerek, servis ömründe çok az sayıda meydana gelmesine izin verilebileceği ifade edilir. Çünkü bu tekrarlı tersinir yükler ile erken yorulma ve daha yüksek kapasite kayıpları görülür.

6) Dolayısıyla, EN 13230-6:2020 standardında travers dizayn metotlarının limit durum dizayn metoduna dayalı olarak modernleştirilmesi ile başlayan yeni sürecin test prosedürlerinin de değinilen bu maddeler doğrultusunda güncellenmesi ile devam etmesi gerekmektedir.

Sonuç olarak; traverslerde kullanılmakta olan çelik donatıların elektrik iletkenliği ve korozyon sorunları olduğu gibi öngerilmeli sistemin erken yorulma ve kapasite kayıpları da ayrı bir dezavantajdır. Günümüzde gelişmiş ülkelerde çelik donatıların yerini almaya başlayan fiber takviyeli polimer (FRP) donatıların demiryolu traverslerinde öngerilmesiz olarak kullanımı alternatif bir çözüm olarak görülmüş, üretilen ön-prototiplerde statik yüklemeli deneyler yapılarak konu araştırılmışıtır.

\section{Metot}

$\mathrm{Bu}$ çalışma kapsamında değerlendirmeye alınan FRP donatılar, reçine matrisi içerisine gömülmüş, yüksek dayanımlı liflerden oluşan kompozit malzemelerdir. FRP donatıların yüksek çekme dayanımı, yüksek yorulma ömrü, yüksek elektrik yalıtkanlığı ve yüksek çevresel dayanıklılığa sahip olması [17], [18], [19] ve tüm bu avantajları ile öngerilmesiz tasarım şekline uygun olmas1 ve projede kullanılan FRP ürünlerin ülkemizde de üretilebilmesi tercih sebebi olmuştur.

Günümüzde, dünyada pek çok ülkede FRP donatı ve profilleri kullanılarak oluşturulmuş yap1 örnekleri bulunmaktadır. $\mathrm{Bu}$ yeni nesil kompozit malzemelerin kullanımı, üstün mekanik dayanımlarının yanı sıra hafifliği, korozyona dayanımı ve kimyasallara karşı yüksek direnç göstermesi, elektrik yalıtımı gibi özelliklerinden dolayı giderek yaygınlaşmaktadır. Özellikle karbon fiber takviyeli polimerler (carbon fiber reinforced polymers, CFRP) uzay, havacilik, rüzgar türbinleri gibi yüksek nitelikli projelerin vazgeçilmezi haline gelmiş, rakiplerinden üstün birçok niteliğe sahip, dünyada sayılı ülkede üretilebilen katma değeri yüksek, gelecek vadeden ürünlerdir. Kuzey Amerika, Avrupa ve Japonya'da çok sayıda betonarme yapı FRP donatısı kullanılarak inşa edilmekte veya güçlendirilmektedir [17]. Uzun yıllar bakım ve boya gibi ek bir hizmete ihtiyaç duymamaları bu malzemeleri diğer alanlarda olduğu gibi inşaat sektöründe birçok malzemenin alternatifi olma yönünde avantajlı konuma getirmektedir [18]. Karbon lifler su emmez ve her türlü alkali ve çözücüye karşı dirençlidir [19]. Günümüzde korozyon hasarını engellemek için (sorunu kaynağında çözecek) alternatif bir çözüm yöntemi olarak, çelik donatı çubuklarının yerine antikorozif malzemelerin, fiber takviyeli polimerlerin (FRP) kullanılmasını önerilmektedir [20]. Fiber takviyeli polimer donatılar kullanıldığında korozyonun ana sorun olmaktan çıktığını, zira bu donatıların oldukça durabil olduklarını belirtilmektedir [21]. Karbonfiber malzemelerin, çelik donatıların dışında, cam-fiber ve aramid-fiber gibi diğer alternatiflere 
göre de çevresel etkilere dayanıklılık açısından en iyi segmenti oluşturduğu CNR-DT 203/2006 k1lavuzunda belirtilmektedir [22].

$\mathrm{Bu}$ yüksek performanslı ürünlerden maksimum fayda elde etmek için öngerilmesiz tasarım kullanılacaktır. Giriş bölümünde detaylı aktarıldığı üzere öngerilmeli traverslerde kapasite kayıpları ve erken yorulma söz konusudur. Literatürde belirtildiği üzere; mevcut "öngerilmesiz" traversler, öngerilmeli rakiplerine göre, demiryolu bakım masraflarını düşürme ve yüksek ömür sergileme potansiyeline sahiptir [23] ve yüksek düzeyli titreşimlerde sönümleme katsayılarl; öngerilmesiz elemanlar için $\% 5$ ve öngerilmeli elemanlarda $\% 2$ olarak verilmektedir [24]. Nitekim kısmi öngerilmeli elemanların enerji sönümleme kabiliyeti, eşdeğer boyut ve dayanımdaki konvansiyonel pasif donatılı betonarme elemanlardan $\% 15$ daha azdır [13]. Ülkemizde daha önce, "ithal" dairesel CFRP donatılar ve B58 tipi travers geometrisi kullanılarak konu deneysel olarak araştırılmış ve olumlu sonuçlar elde edilmiştir. Deneylerde kullanılan B58 tipi traverslerin dinamik dizayn yükü $\left(\mathrm{Fr}_{0}\right) 125 \mathrm{kN}$ iken, eş-boyutlu ve $\% 28$ daha düşük donatı oranına sahip CFRP donatılı numunelerin yorulma esaslı dizayn yükü $\left(\mathrm{Fr}_{0,05}\right) 190 \mathrm{kN}$ olarak tespit edilmiştir [25]. Bu makalede söz konusu çalışmanın devamı olarak, B70 tipi travers geometrisi kullanılarak, bu kez "yerli" üreticiden temin edilen CFRP lamine plakalar, alanında dünyada ilk olarak, Şekil 6'da görüleceği üzere demiryolu traversleri içerisinde donatı olarak kullanılmıştır. Söz konusu CFRP plakaların çekme dayanımı $1500 \mathrm{MPa}$ iken elastisite modülü $160 \mathrm{GPa}$ 'dır.

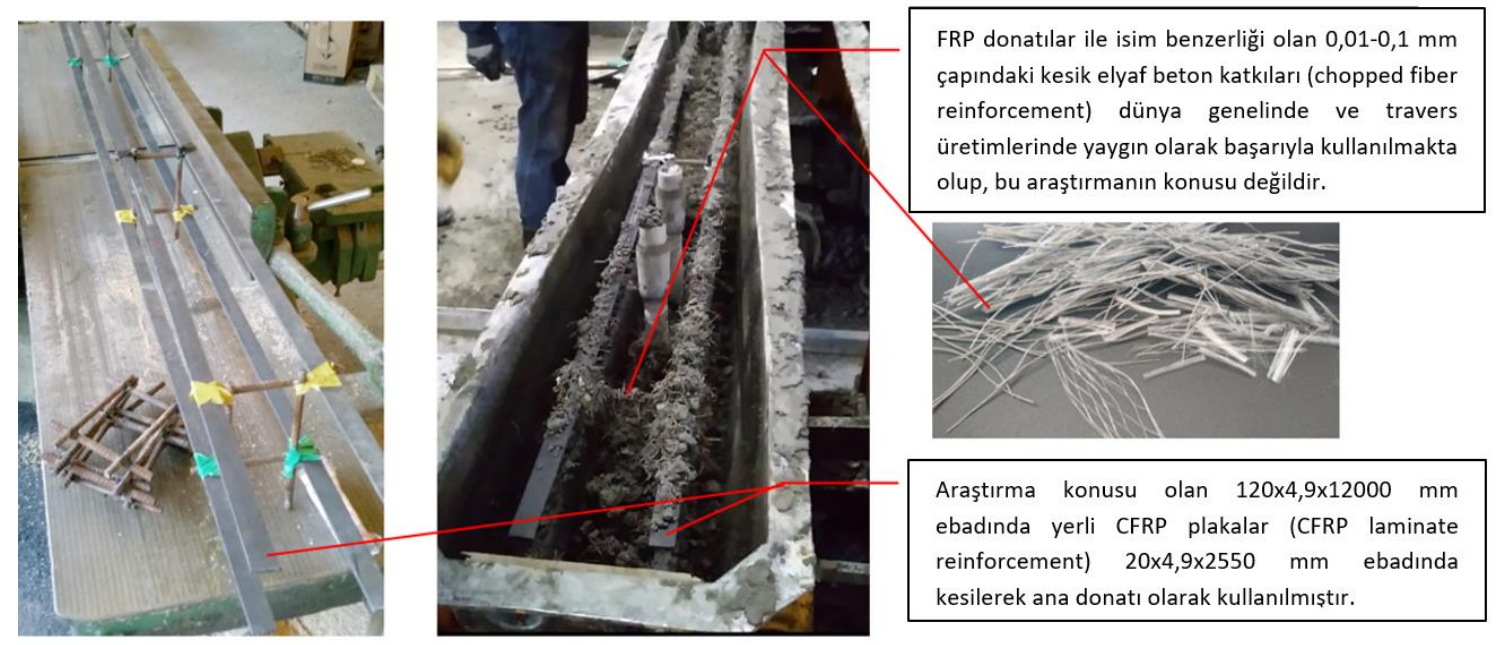

Şekil 6. Yerli lamine CFRP plaka donatılı traverslerin üretim aşamaları ve kesik elyaflarla karşılaştırması

Demiryollarında hâlihazırda cam fiber takviyeli polimer donatılar (GFRP) Şekil 1.d'de görülen "slab-track" tarzı kesintisiz döşeme betonlarında (elektrik yalıtkanlığı istenen lokasyonlarda) kullanılmaktadır. Ancak bu çalışma kapsamında monoblok travers kesiti içerisinde kullanılarak, CFRP ve çelik donatılı traversler ile performansı karşılaştırılmıştır. Yerli bir firmadan temin edilen cam fiber takviyeli polimer donatılar (glass fiber reinforced polymer rods, GFRP) Şekil 7'den görülebileceği üzere kullanılarak travers numunesi üretilmiştir. Kullanılan GFRP donatıların çekme dayanımı $700 \mathrm{MPa}$ iken elastisite modülü $40 \mathrm{GPa}$ 'dır. İnşaat mühendisliği yapılarında gerek elektrik yalıtkanlığı gerekse korozyon dayanıklılı̆̆ faydaları gözetilerek git gide yaygınlaşmaya başlayan bu donatıların traverslerde kullanımı konusunda ülkemizde henüz akademik araştırma yapılmamıştır. GFRP donatıların korozyon direnci ve elektrik yalıtkanlığ yüksek olsa da literatür özetinde sunulduğu üzere düşük elastisite modülü nedeniyle yorulma dayanımı diğer FRP donatılara göre düşüktür ve koruyucu epoksi kaplamasının çatlaması halinde alkali dayanımı düşüktür. Demiryolu yükleri ise karayollarına nazaran çok daha yüksek darbe yüklerinin görüldüğ̈ dinamik tekrarlı yükler görülen bir özelliğe sahiptir ve hatlarımız donma çözülme dâhil birçok zararlı etkene yüksek düzeyde maruz kalabilmektedir. Bu doğrultuda söz 
konusu ürünlerin kullanıldığı mevcut döşeme tipi traverslerin yeterli servis ömrüne sahip olup olmayacağının tahkik edilmesi açısından faydalı olacağı düşünülerek çalışmaya dâhil edilmiştir.
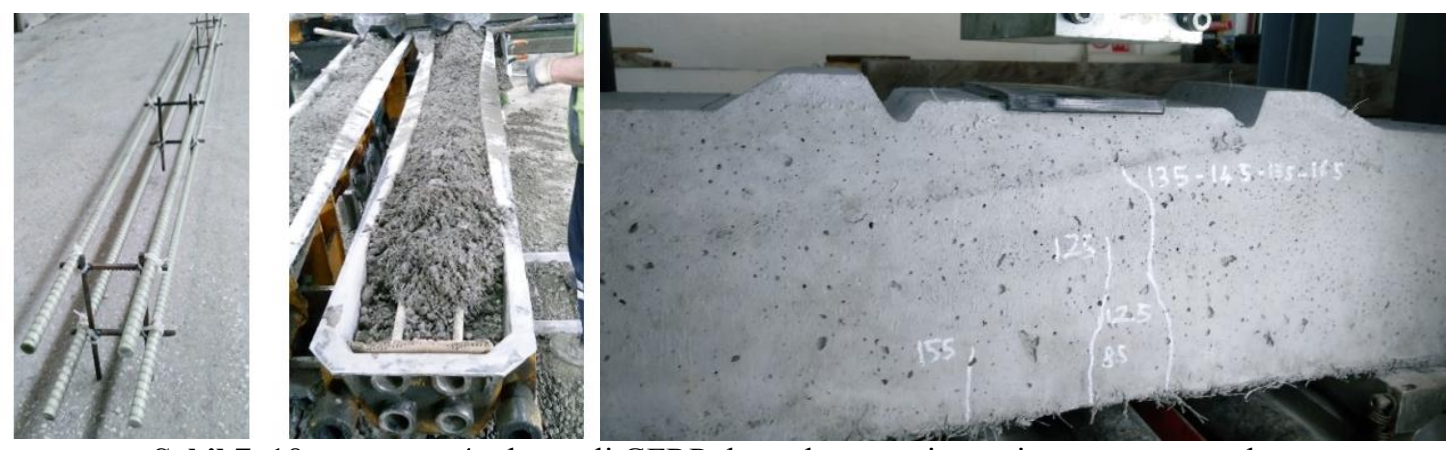

Şekil 7. $18 \mathrm{~mm}$ çapta 4 adet yerli GFRP donatılı traversin üretim ve test aşamaları

FRP donatıların çekme dayanımları yüksek olsa da, "kesme dayanımı" çelik donatılara göre düşüktür. (Yaklaşık 40-80 MPa düzeylerindedir.) Bu yüzden FRP donatıların kesmeye maruziyeti özellikle değerlendirilmelidir. Traverslerin kesme dayanımlarının artırılması için çelik etriyeler kullanılması, çelik donatı kullanımıyla benzer dezavantajlar nedeniyle mümkün olmamıştır. Bunun yerine, traversler içerisinde, daha önce literatürde çokça araştırılan ve hâlihazırda gelişmiş ülkelerde travers üretiminde kullanılmakta olan, kesik elyaf katkılar (chopped fibers) Şekil 6'dan görülebileceği üzere kullanılmıştır. Dolayısıyla bu ön-prototiplerde etriye kullanılmamış ancak travers betonunun titreşimle yerleştirilmesi esnasında, donatıların konumlarının bozulmaması için Şekil 6 ve Şekil 7'den görülebileceği üzere; 1 travers kalıbı için 4 adet metal sehpa kullanılmıştır.

\section{Bulgular}

$\mathrm{Bu}$ araştırma kapsamında, CFRP lamine plakalar ve GFRP dairesel donatılar kullanılarak üretilen traversler EN 13230 doğrultusunda kür işlemi yapıldıktan sonra alınan beton numunelerinin dayanımları ölçülerek standartta istenen minimum C45/55 dayanım sınıfında olduğu teyit edilmiş, akabinde demiryolu standartlarında travers tasarımı onay testlerinden ilki olan "ray mesnedinde statik yüklemeli pozitif moment" deneyleri yapılmıştır. Deney görselleri Şekil 7 ve 8 'de, karşılaştırmalı grafik Şekil 9'da sunulmuştur. Söz konusu deneyin uygulanma prosedürü ve çatlak değerlendirmeleri detaylı olarak literatürde bulunmaktadır [25].

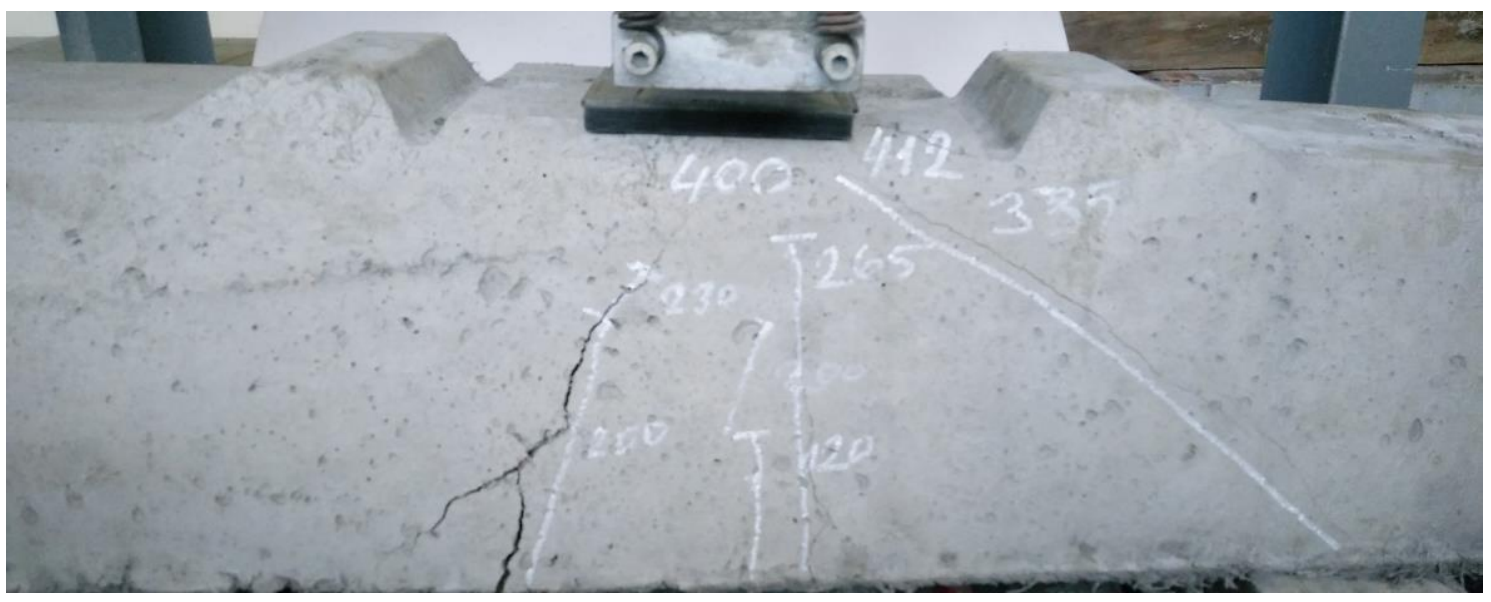

Şekil 8. 20 x 4,9 mm enkesitte 4 adet yerli lamine CFRP plaka donatılı traversin test aşamaları

Deney sonuçlarına göre, 4,9x20 mm en-kesite sahip 4 adet CFRP plaka (toplam $392 \mathrm{~mm}^{2}$ ) kullanılarak üretilen traverslerde gözlemlenen ilk çatlak başlangıcının $\left(\mathrm{Fr}_{\mathrm{r}}\right) 120 \mathrm{kN}, 0,05 \mathrm{~mm}$ 
kalınlığında kalıcı çatlak başlangıcının $\left(\mathrm{Fr}_{0,05}\right) 230 \mathrm{kN}$ ve kırılma yükünün $412 \mathrm{kN}$ olduğu tespit edilmiştir. Diğer FRP tipi olan $18 \mathrm{~mm}$ çapa sahip 4 adet GFRP donatı (toplam $1017 \mathrm{~mm}^{2}$ ) kullanılarak üretilen traverslerde gözlemlenen ilk çatlak başlangıcının $\left(\mathrm{Fr}_{\mathrm{r}}\right) 85 \mathrm{kN}, 0,05 \mathrm{~mm}$ kalınlığında kalıcı çatlak başlangıcının $\left(\mathrm{Fr}_{0,05}\right) 125 \mathrm{kN}$ ve kırılma yükünün $165 \mathrm{kN}$ olduğu tespit edilmiştir. B70 tipi traversler ise 9,4 mm çapında 4 adet HTS tipi çelik donatı öngerilme kuvveti uygulanarak üretilmekte, gözlemlenen çatlak başlangıcının minimum $150 \mathrm{kN}$, kalıcı çatlak başlangıcının minimum $270 \mathrm{kN}$ ve kırılma yükünün minimum $375 \mathrm{kN}$ olması şartları aranmaktadır. Literatür özetinde detaylı sunulduğu üzere; öngerilmeli traverslerde yorulma esaslı dizayn yükü öngerilme kuvvetinin tükendiği $\mathrm{Fr}_{0}$ yükü iken, öngerilmesiz traverslerde $\mathrm{Fr}_{0,05}$ yüküdür. Nitekim Fransa'da geliştirilen U3 tipi öngerilmesiz traversler için French Railways standards'da istenen tasarım alt sinırı $\left(\mathrm{Fr}_{0.05}\right) 125 \mathrm{kN}$ 'dur [25].

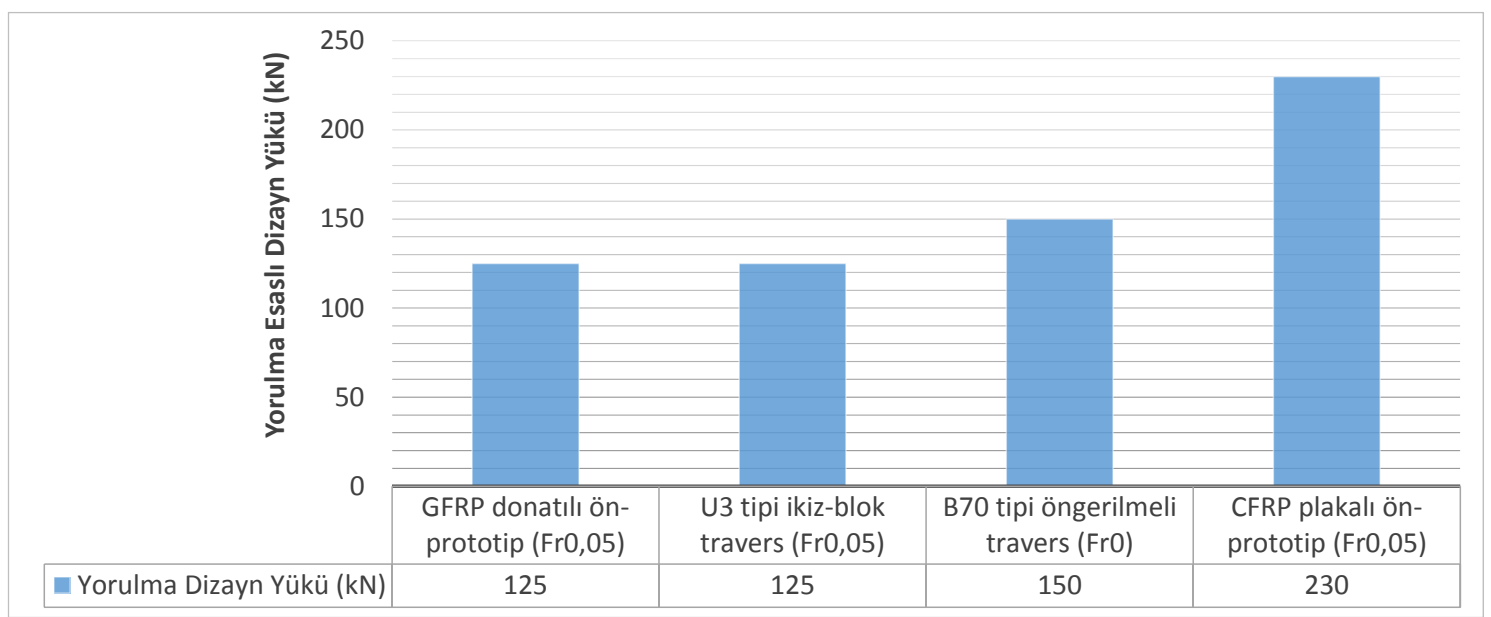

Şekil 9. Dünyada yaygın olarak kullanılan B70 tipi öngerilmeli mono-blok ve U3 tipi öngerilmesiz ikizblok traversler ile FRP donatılı ön-prototiplerin yorulma esaslı dizayn yüklerinin karşılaştırılması

\section{Sonuç}

Bu çalışma kapsamında, demiryolu traverslerinin erken deformasyonunda etkili olan faktörler ve dünya genelinde son yıllarda geliştirilen çözümler sunulmuştur. Günümüzde gelişmiş ülkelerde çelik donatıların yerini almaya başlayan fiber takviyeli polimer (FRP) donatıların demiryolu traverslerinde kullanımının alternatif bir çözüm olabileceği öngörülmüş, demiryolu standartlarında travers tasarımı onay testlerinden ilki olan ray mesnedinde statik yüklemeli pozitif moment deneyleri yapılmıştır. Elde edilen sonuçlara göre, CFRP plakalar ile üretilen bu ilk inovatif traverslerin dünyada yaygın olarak kullanılan öngerilmeli ve öngerilmesiz rakiplerinden ve yaklaşık eşdeğer maliyete sahip GFRP donatılı traverslerden -yorulma dizayn yükü bakımından- üstün ve oldukça pozitif sonuç koyduğu görülmüştür. Geliştirilen prosesin uzun servis ömrü vadetmesi ile hem traverslerin hem de raylar, zemin, tünel, viyadük, tren setleri gibi çok daha pahalı diğer demiryolu bileşenlerinin yapım-bakım-işletim masraflarını düşürmesi ve milyonlarca travers üretiminin neden olduğu çevresel zararların azaltılması gibi büyük faydalar sağlaması mümkündür. Bunun yanı sıra bariz bir üretim kolaylığı ve tasarrufu da sağlayacaktır. Bu prosesle öngerilme işlemi ve etriye üretimi için gerekli hammadde, yakıt, enerji ve işçilikten tasarruf edilebilecektir. Ayrıca CFRP plakaların elektriksel olarak yalıtkan olması nedeniyle, hem elektrifikasyonlu hatların korozyon etkisi bertaraf edilebilecek, hem de seyir emniyetini sağlayan "sinyalizasyon sistemlerinin" korunması da sağlanacaktır. FRP donatıların yeni bir teknoloji olması ve inşaat mühendisliği yapılarında yeni yeni kullanılmaya başlaması nedeniyle donatı temin maliyetinde \%50-100 düzeylerinde artış meydana gelecektir. Ancak üretim kolaylığı ve yüksek servis ömrü gibi avantajları ile özellikle "yeni nesil" traverslere nazaran oldukça fizibil çözümler üretilmesi öngörülmektedir. Ayrıca, günümüzde demiryolu işletim kapasitesi arttıkça, bakım işlemleri için ayrılabilecek süreler azalmış, gece saatlerinde birkaç saat içerisinde 
tamamlanabilecek, düşük bakım gerektiren traversler kullanılması "mecburiyet" halini almıştır. Nihai travers tasarım boyutlarının ve donatı kesitlerinin belirlenmesi için çok sayıda kombinasyon ile deneysel çalışma yapılması gerekmekte olup, bu çalışmalar imkanlar dahilinde devam etmektedir. Üretilecek bu yeni nesil traverslerin UIC yeterliliği açısından gerekli olan dinamik ve uzun süreli yorulma testlerinin de yapılması gerekmektedir.

\section{Teşekkür}

Bu çalışmada desteklerinden dolayı TCDD Sivas Beton Travers Fabrikası Müdürü Sn. Ali KARABEY'e, CFRP plaka ve elyaf üreticileri dowAksa firması yetkilisi Sn. Ilgaz DOĞAN'a ve ve Polyfibers firması yetkilisi Sn. Faraz MALIK'e teşekkürlerimizi bildiririz.

\section{Kaynakça}

[1] W. Ferdous, A. Manalo, "Failures of mainline railway sleepers and suggested remedies - review of current practice," Engineering Failure Analysis, vol. 44, pp. 17-35, April 2014.

[2] J. Taherinezhad, M. Sofi, P. Mendis, T. Ngo, "Strain rates in prestressed concrete sleepers and effects on cracking loads," Electronic Journal of Structural Engineering, vol. 17, no. 1, pp. 65-75, January 2017.

[3] W. Ferdous, A. Manalo, G. V. Erp, T. Aravinthan, S. Kaewunruen ve A. M. Remennikov, "Composite railway sleepers - recent developments, challenges and future prospects," Composite Structures, vol. 134, pp. 158-168, 2015, doi: 10.1016/j.compstruct.2015.08.058

[4] C. Esveld, Modern railway track, Zaltbommel - The Netherlands: MRT-Productions, 2014

[5] R. You, D. Li, C. Ngamkhanong, S. Kaewunruen, "Fatigue life assessment method for prestressed concrete sleepers," Frontiers in Built Environment, vol. 3, no. 68, pp. 1-13, November 2017, doi: https://doi.org/10.3389/fbuil.2017.00068

[6] A. M. Remennikov, M. H. Murray, S. Kaewunruen, "Dynamic design guidelines for prestressed concrete sleepers", 2008. [Online]. Avaliable: https://ro.uow.edu.au/engpapers/492/ [Accessed: 30.09.2020]

[7] J. R. Edwards, Z. Gao, H. E. Wolf, M. S. Dersch, Y. Qian, "Quantification of concrete railway sleeper bending moments using surface strain gauges," Measurement, vol. 111, pp. 197-207, July 2017, doi: http://dx.doi.org/10.1016/j.measurement.2017.07.029

[8] A. Jokūbartıs, G. Marc iukaitis, J. Valivonis, "Influence of technological and environmental factors on the behavior of the reinforcement anchorage zone of prestressed concrete sleepers," Construction and Building Materials, vol. 121, part C, pp. 507-518, September 2016, doi: http://dx.doi.org/10.1016/j.conbuildmat.2016.06.025

[9] R. J. Quirós-Orozco, J. R. Edwards, Y. Qian, M. S. Dersch, "Quantification of loading environment and flexural demand of prestressed concrete crossties under shared corridor operating conditions," Journal of Transportation Research Record, vol. 2672, no. 10, pp. 136-145, August 2018, doi: https://doi.org/10.1177/0361198118793500

[10] J. Sýkorová, J. Bártová, P. Štemberk, "Prestressed concrete sleeper under extreme loading conditions" 18th International Conference Engineering Mechanics, Svratka, Czech Republic, pp. 312-313, 2012.

[11] H. Isozaki, J. Oosawa, Y. Kawano, R. Hirasawa, S. Kubota, S. Konishi, "Measures against electrolytic rail corrosion in Tokyo metro subway tunnels," Procedia Engineering, vol. 165, pp. 583 - 592, December 2016, doi: https://doi.org/10.1016/j.proeng.2016.11.754

[12] T. J. Barlo, A.D. Zdunek, "Stray current corrosion in electrified rail systems, northwestern university final report," 1995 [Online]. Avaliable: https://rosap.ntl.bts.gov/view/dot/13213/dot_13213_DS1.pdf

[13] ACI-ASCE Committee 423, "State-of-the-art report on partially prestressed concrete, ACI 423.5R99," 1999 [Online]. Avaliable: http://civilwares.free.fr/ACI/MCP04/4235r_99.pdf 1999.

[14] S. Kaewunruen, "Experimental and numerical studies for evaluating dynamic behaviour of prestressed concrete sleepers subject to severe impact loading," PhD dissertation, School of Civil Mining \& Environmental Engineering, University of Wollongong, New South Wales, 2007

[15] H. E. Wolf, "Flexural behavior of prestressed concrete monoblock crossties," Master of Science Thesis, Civil Engineering, Graduate College of the University of Illinois, Urbana-Champaign, Illinois, 2015 [16] N. Ö. Bezgin, "An insight into design of prefabricated and prestressed concrete monoblock railway ties for service loads," Challenge Journal of Structural Mechanics, vol. 4, no. 4, pp. 126-136, December 2018, doi: https://doi.org/10.20528/cjsmec.2018.04.001 
[17] E. Vatangül, "Kompozit malzemelerin mekanik özelliklerinin belirlenmesi ve ansys 10 programı ile 1sil gerilme analizi," [Online]. Available: http://ansys.deu.edu.tr/wpcontent/uploads/cmdm/621/1450959921_EREN_VATANGUL_2002508078.pdf [Accessed: 30.09.2020]. [18] F. Aydın, "Cam lifi takviyeli plastik (gfrp) kompozit ve beton ile üretilen hibrit yapı elemanlarının mekanik performansının araştırılması," Doktora Tezi, Fen Bilimleri Enstitüsü, Sakarya Üniversitesi, Sakarya, 2011

[19] B. Felekoğlu, “Alternatif yap1 malzemeleri," 2019. [Online]. Avaliable: kisi.deu.edu.tr/burak.felekoglu/04.Polipart2.pdf [Accessed: 30.09.2020]

[20] G. Yavuz, "Lif takviyeli polimerlerin betonarme kirişlerde donatı olarak kullanımı," e-Journal of New World Sciences Academy. vol. 6, no.4, October 2011.

[21] R. Fico, "Limit states design of concrete structures reinforced with frp bars," Ph. D. Dissertation, Materials and Structures Engineering, University of Naples Federico II, Napoly, 2008

[22] National Research Coincil-Advisory Commitee on Technical Recommendations for Construction (CNR), Rome, Italy, Guide for the design and construction of concrete structures reinforced with fiberreinforced polymer bars (CNR-DT 203/2006), 2007. [Online]. Available: https://www.cnr.it/en/node/2639 [Accessed: 30.09.2020].

[23] T. Abadi, L. Le Pen, A. Zervos, W. Powrie, "Improving the performance of railway track through ballast interventions," Journal of Rail and Rapid Transit, vol. 232, no. 2, pp. 337-355, October 2016, doi: https://doi.org/10.1177\%2F0954409716671545

[24] A. Mårtensson, M. Nilsson, "Dynamic analysis of pedestrian load models for footbridges," Master of Science Thesis, Department of Civil and Environmental Engineering, Chalmers University of Technology, Göteborg, 2014

[25] F. Çeçen, "Karbon - fiber donatıyla öngerilmesiz monoblok demiryolu beton traversi geliştirilmesi," Yüksek Lisans Tezi, Fen Bilimleri Enstitüsü, İnşaat Mühendisliği Ulaştırma ABD, Gazi Osman Paşa Üniversitesi, Tokat, 2019

\section{Özgeçmiş}

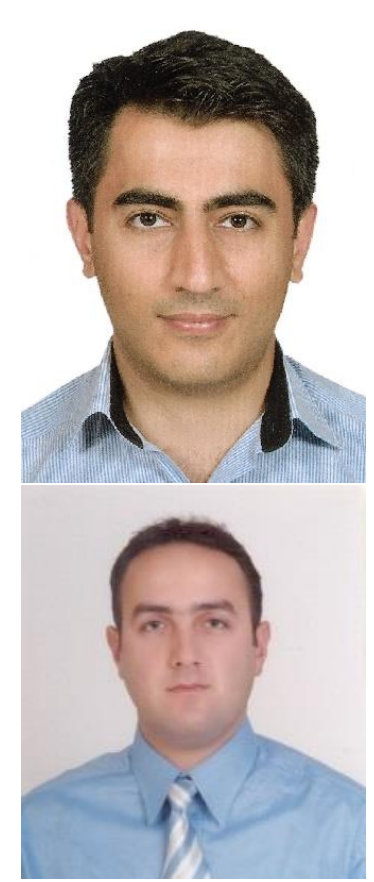

\section{Ferhat ÇEÇEN}

Yüksek Lisans eğitimini "Karbon - Fiber Donatıyla Öngerilmesiz Monoblok Demiryolu Beton Traversi Geliştirilmesi” teziyle Gaziosmanpaşa Üniversitesinde tamamlamış, halen Erciyes Üniversitesi'nde doktora eğitimine devam etmektedir. CFRP, GFRP ve çeşitli yerli ürünlerle milli demiryolu traverslerinin geliştirilmesi amaçlı ar-ge ve patent çalışmaları devam etmektedir.

E-Posta: ferhatcecen@tcdd.gov.tr

\section{Bekir AKTAŞ}

Lisans ve Yüksek Lisans eğitimini Erciyes Üniversitesi, Doktora Eğitimini ise Süleyman Demirel Üniversitesinde tamamlamış, halen Erciyes Üniversitesi İnşaat Mühendisliği Bölümü Ulaştırma Anabilim Dalında öğretim üyesidir. Ulaştırma alanında yerli ve yabancı dergilerde yayımlanan birçok makalesi bulunmaktadır.

E-Posta: baktas@erciyes.edu.tr

\section{Beyanlar:}

Bu makalede bilimsel araştırma ve yayın etiğine uyulmuştur. Tüm yazarların eşit oranda katkısı olmuştur. 